\title{
Resíduos de Serviços de Saúde: o que mudou na legislação?
}

\section{Waste from Health Services: what has changed in the legislation?}

\author{
Lucas Eduardo Carneiro', Giovana Alves Santos², \\ Danielly Negrão Guassú Nogueira ${ }^{3}$
}

\begin{abstract}
Resumo
Introdução: os Resíduos de Serviços de Saúde (RSS) têm sido uma fonte de preocupação para os gestores hospitalares, pois necessitam atender às exigências legais; nos últimos anos houve mudanças no Brasil com a publicação da atual Resolução de Diretoria Colegiada (RDC) 222/18, que normatiza o gerenciamento interno dos resíduos. Objetivo: comparar a RDC 306/04 com a RDC 222/18 quanto ao gerenciamento de Resíduos de Serviços de Saúde, bem como apresentar as implicações da legislação em vigência. Material e Método: trata-se de uma pesquisa exploratória e descritiva, de abordagem qualitativa do tipo documental; para tal, criou-se um roteiro de análises baseado nas etapas de gerenciamento dos RSS; os resultados foram apresentados em tabelas por grupos (A, B, C, D e E) que foram as categorias documentais para a comparação da legislação RDC 306/04 com a RDC 222/18. Resultados: observou-se importantes mudanças na lei atual, com impacto para os gestores e profissionais que atuam em hospitais, como o descarte de bolsas de sangue e peças anatômicas caracterizadas como A1, liberação de descarte de equipamentos de proteção individual (EPIs) como resíduos do Grupo D comum, seringas e agulhas podem ser desconectadas quando tiverem o dispositivo de segurança, novos critérios para descarte de oito grupos de medicamentos, entre outras. Discussão: as mudanças citadas necessitam ser incorporadas nos planos de gerenciamento, planejamento de novos fluxos de segregação de resíduos e aquisição de novos coletores que em médio prazo podem contribuir na redução de custo financeiro, e diminuição dos impactos ambientais desses resíduos quando descartados de forma segura. Conclusão: ao comparar as duas legislações, o presente estudo contribui para direcionar as adequações necessárias, a fim de atender a atual legislação, com informações diretas para orientar novos critérios de classificação, acondicionamento, tratamento e destinação final para o gerenciamento seguro dos resíduos nos serviços de saúde.
\end{abstract}

Palavras-chave: Enfermagem; Resíduos de Serviços de Saúde; Legislação; Plano de Gerenciamento de Resíduos de Serviços de Saúde.

\footnotetext{
${ }^{1}$ Graduação em Enfermagem pela Universidade Estadual de Londrina (UEL), Londrina, Paraná, Brasil. Pós-graduando nível lato sensu em Residência Multiprofissional em Saúde da Família na Autarquia Municipal de Saúde (AMS), Apucarana, Paraná, Brasil. E-mail: lucccaseduardo@gmail.com

${ }^{2}$ Mestranda no Programa de Pós-graduação em Enfermagem da Universidade Estadual de Maringá (UEM), Maringá, Paraná, Brasil.

${ }^{3}$ Doutorado em Gerenciamento em Enfermagem pela Escola de Enfermagem da Universidade de São Paulo (EEUSP), São Paulo, São Paulo, Brasil. Docente do Departamento de Enfermagem da Universidade Estadual de Londrina, Londrina, Paraná, Brasil.
} 


\begin{abstract}
Introduction: Waste from Health Services (RSS) has been a source of concern for hospital managers, as they need to meet legal requirements; in recent years there have been changes in Brazil with the publication of the current Resolution of the Collegiate Board 222/18, which regulates the internal management of waste. Objective: to compare Resolution of the Collegiate Board 306/04 with Resolution of the Collegiate Board 222/18 regarding the management of RSS, as well as present the implications of the legislation in force. Material and Method: this is an exploratory and descriptive research, with a qualitative approach of the documentary type; for this, an analysis script was created based on the steps of managing the RSS; the results were presented in tables by groups (A, B, C, $\mathrm{D}$ and $\mathrm{E}$ ) which were the document categories for the comparison of legislation Resolution of the Collegiate Board 306/04 with Resolution of the Collegiate Board 222/18. Results: important changes were observed in the current law, with an impact on managers and professionals working in hospitals, such as the disposal of blood bags and anatomical parts characterized as A1, release of disposal of Personal Protective Equipment as waste from Group D common, syringes and needles can be disconnected when they have the safety device, new criteria for disposing of eight groups of drugs, among others. Discussion: the aforementioned changes need to be incorporated into management plans, planning new waste segregation flows and acquisition of new collectors that in the medium term can contribute to reducing the financial cost, and reducing the environmental impacts of these wastes when disposed of safely. Conclusion: by comparing the two legislations, this study contributes to direct the necessary adjustments, in order to meet the current legislation, with direct information to guide new classification, packaging, treatment and final disposal criteria for the safe management of waste in the services of health.
\end{abstract}

Keywords: Nursing; Waste from Health Services; Brazilian legislation; Management Plan of Waste from Health Services.

\section{Introdução}

Os Resíduos de Serviços de Saúde (RSS) têm sido uma fonte de preocupação para os gestores de saúde no terceiro milênio, quando os modelos de gestão devem ter suas decisões pautadas na responsabilidade ambiental e social para o desenvolvimento econômico. Isso implica defender as políticas e práticas sustentáveis, como estimular o uso mais consciente de recursos, evitando desperdícios e melhorando a alocação de seus recursos financeiros. Isto tem suscitado na criação de políticas públicas e legislações, possuindo como eixos de orientação a sustentabilidade do meio ambiente e a preservação da saúde. ${ }^{(1)}$

Grande parte das atividades de saúde desenvolvidas durante a prestação de assistência e cuidado utiliza recursos materiais, como insumos, medicações, instrumentais cirúrgicos e gêneros alimentícios, muitos de uso único e descartáveis, que dão origem aos RSS.
Os RSS são classificados como resíduos perigosos e vêm assumindo grande importância nos últimos anos, não pelo ponto de vista da quantidade gerada, que varia de $1 \%$ a $3 \%$ do montante total dos resíduos sólidos urbanos gerados em um município, mas pelo risco que apresentam quando não gerenciados corretamente. ${ }^{(2-4)}$

O gerenciamento de RSS é um conjunto de procedimentos de gestão, planejados e implementados a partir de bases científicas e técnicas e normativas legais, com o objetivo de minimizar a produção dos resíduos e proporcionar um encaminhamento seguro a estes, visando a proteção dos trabalhadores e a preservação da saúde pública, dos recursos naturais e do meio ambiente. ${ }^{(5)}$

As duas principais legislações em vigor no Brasil relacionadas aos RSS são: a Resolução de Diretoria Colegiada (RDC) n ${ }^{\circ} 222$, de 28 de maio de 2018, da Agência Nacional de Vigilância Sanitária (Anvisa) - que substituiu a RDC n ${ }^{\circ} 306$, de 7 de dezembro de 2004, que define a gestão interna e tem 
as seguintes etapas: segregação, acondicionamento, identificação, transporte interno, armazenamento temporário, tratamento e armazenamento externo; ${ }^{(6)}$ e a do Conselho Nacional de Meio Ambiente (CONAMA), por meio da Resolução $n^{0}$ 358, de 29 de abril de 2005, que define as leis da gestão externa ao estabelecimento de saúde, contemplando as etapas de coleta, transporte externo e destinação final. ${ }^{(7)}$

Todas as instituições de saúde devem ter um Plano de Gerenciamento de RSS (PGRSS) com a descrição de todas as etapas gerenciais que devem ser descritas de acordo com os critérios de classificação, infraestrutura local e rede de serviços e parceiros do município, articulando com a realidade de cada instituição. ${ }^{(8)}$

Esses resíduos produzidos nos serviços de saúde são classificados como grupos A, B, C, D e E. Os do Grupo A são aqueles com possível presença de agentes biológicos; os do Grupo B, os que contêm substâncias químicas que podem apresentar risco à saúde pública ou ao meio ambiente; os do Grupo C são os radioativos; os do Grupo D, resíduos comuns recicláveis e não recicláveis que possam ser equiparados aos resíduos domiciliares, e, ainda, os do Grupo E: materiais perfurocortantes ou escarificantes. ${ }^{(6)}$

Existe uma tendência de crescimento do volume de RSS; diante desta problemática, profissionais de diversas áreas estão discutindo os inúmeros aspectos que perpassam o tema, seja técnico, legal, financeiro, institucional ou outros. Daí a extensa bibliografia que o trata e que o mantém em evidência, sendo uma temática muito atual. ${ }^{(1)}$

Os hospitais enquanto serviços de saúde têm tido dificuldades para operacionalizar o PGRSS como determina a legislação, gerando desperdícios e comprometendo a saúde da população. Embora se reconheça a importância da gestão dos RSS, há ainda certa dificuldade para sua operacionalização, em virtude da pouca experiência das administrações municipais e gestores hospitalares em equacionar com eficiência suas determinações legais, devido à diversidade de normas e regulamentações sobre o tema.
Em muitos hospitais o enfermeiro é o responsável técnico pelo PGRSS, e deve ter visão ampla de gerenciamento, focando na análise do processo de trabalho e na gestão de custos, que é uma ferramenta gerencial essencial e sempre um forte argumento para buscar apoio da direção na obtenção de recursos para melhorias e adequações necessárias para atender as exigências legais mínimas para a segurança dos trabalhadores e do meio ambiente.

Este estudo justifica-se, pois as atividades que envolvem qualquer etapa do gerenciamento de Resíduos de Serviços de Saúde, sejam eles públicos ou privados, são regulamentadas pela RDC 222/18 da Anvisa. Essa resolução foi implantada no ano de 2018, após 14 anos de vigência da RDC 306/04, com isso, muitos profissionais e instituições ainda desconhecem as implicações desta nova resolução e ainda não incorporaram as exigências da nova legislação. Dessa maneira, este estudo poderá direcionar, informar e atualizar os profissionais que atuam no gerenciamento de resíduos, sendo essa a justificativa do estudo.

A comparação das duas legislações com foco nas mudanças práticas para os serviços de saúde, evidenciando itens que foram excluídos ou mantidos e as novas determinações da recente legislação, otimizará os planos de adequações e melhorias e pode evitar multas e penalidades junto aos órgãos fiscalizatórios, favorecendo um gerenciamento de RSS mais seguro, alinhado com as práticas globais de sustentabilidade.

Destarte, tornam-se necessários o conhecimento e o envolvimento por parte dos enfermeiros quantos às novas recomendações da legislação para o plano estratégico de melhoria e adequação do PGRSS. Diante desta problemática, a pergunta norteadora do presente estudo foi: "quais as mudanças provocadas pela recente legislação de RSS (RDC 222/18) na prática gerencial dos RSS nos hospitais?".

Portanto, este estudo objetivou comparar a RDC 306/04 com a RDC 222/18 quanto ao gerenciamento de Resíduos de Serviços de Saúde (RSS), de modo a apresentar as implicações da legislação em vigência. 


\section{Material e Método}

Trata-se de uma pesquisa exploratória descritiva de abordagem qualitativa do tipo documental, realizada por meio da análise documental da legislação da Anvisa que regula o gerenciamento de RSS no Brasil através da RDC 222/18, a qual substituiu a antiga RDC 306/04.

A pesquisa documental é uma "fonte rica e estável de dados", não implica altos custos, não exige contato com os sujeitos da pesquisa e possibilita uma leitura aprofundada das fontes. Ela é semelhante à pesquisa bibliográfica e o que as diferencia é a natureza das fontes, sendo material que ainda não recebeu tratamento analítico, ou que ainda pode ser reelaborado de acordo com os objetivos da pesquisa. ${ }^{(9-10)}$

O uso da análise documental trabalha, em sua essência, documentos que não sofreram modificações ou análises prévias, e implica na capacidade do pesquisador de compreender, filtrar e interpretar os dados levantados e realizar a união com sua fonte, tornando o trabalho expressivo. ${ }^{(9-10)}$

Para a coleta dos dados foi utilizado um formulário baseado nas etapas de gerenciamento da RDC 222/18 para direcionar a leitura crítica que buscou apreender categorias, de grande valor para o gerenciamento interno do enfermeiro, sendo os grupos A, B, C, D e E das referidas legislações.

Os resultados foram apresentados em figuras para melhor visualização das comparações entre as duas legislações.

O presente estudo está alinhado ao projeto de pesquisa "Sustentabilidade e Gestão de Custos em Saúde", e tem aprovação do Comitê de Ética em Pesquisa (CEP) da Universidade Estadual de Londrina (UEL), Londrina, Paraná, Brasil. CAAE: 21617119.9.0000.5231.

\section{Resultados}

Os resultados estão apresentados em figuras (1 e 2) para facilitar a visualização da comparação das duas legislações, bem como os itens que não constavam na legislação antiga, com foco nas mudanças práticas para os serviços de saúde, evidenciando os itens que foram mantidos e incluídos na legislação RDC 222/18.

As alterações na legislação em estudo podem ser observadas na Figura 1, a seguir, na qual está apresentada a comparação da RDC no 306/04 com a $\mathrm{RDC} \mathrm{n}^{\circ} 222 / 18$.

Figura 1 - Comparação da classificação do manejo dos RSS da RDC 306/04 com a RDC 222/18.

\begin{tabular}{|c|c|c|}
\hline Grupos de resíduos & RDC 306/04 & RDC 222/18 \\
\hline $\begin{array}{c}\text { Grupo A } \\
\text { Resíduo infectante }\end{array}$ & $\begin{array}{c}\text { Resíduos com a possível } \\
\text { presença de agentes } \\
\text { biológicos que, por suas } \\
\text { características, podem } \\
\text { apresentar risco de infecção. }\end{array}$ & $\begin{array}{r}\text { Resíduos com a possível } \\
\text { presença de agentes } \\
\text { biológicos que, por suas } \\
\text { características, podem } \\
\text { apresentar risco de infecção. }\end{array}$ \\
\hline Resíduo químico & $\begin{array}{c}\text { Resíduos de saúde do estado } \\
\text { sólido devem ser dispostos } \\
\text { em aterros de classe 1 } \\
\text { (resíduo perigoso). }\end{array}$ & $\begin{array}{r}\text { Resíduos de saúde devem } \\
\text { ser dispostos de acordo } \\
\text { com o risco. }\end{array}$ \\
\hline INFECTANTE
\end{tabular}


Continuação

\begin{tabular}{|c|c|c|}
\hline \multirow{3}{*}{$\begin{array}{c}\text { Grupo B } \\
\text { Resíduo químico }\end{array}$} & $\begin{array}{l}\text { O descarte de acumuladores de } \\
\text { carga contendo chumbo }(\mathrm{Pb}) \text {, } \\
\text { cádmio }(\mathrm{Cd}) \text { e mercúrio }(\mathrm{Hg}) \text { e } \\
\text { seus compostos deve ser feito } \\
\text { de acordo com a Resolução } \\
\text { CONAMA n } 257 / 1999 .\end{array}$ & $\begin{array}{l}\text { O descarte de pilhas, baterias, } \\
\text { acumuladores de carga e } \\
\text { lâmpadas fluorescentes deve } \\
\text { ser feito de acordo com as } \\
\text { normas ambientais vigentes } \\
\text { no local de geração. }\end{array}$ \\
\hline & $\begin{array}{l}\text { Os resíduos de vacinação } \\
\text { quando não submetidos ao } \\
\text { tratamento em seu local de } \\
\text { geração devem ser devolvidos } \\
\text { para as secretarias de saúde. }\end{array}$ & $\begin{array}{l}\text { Os resíduos de vacinação } \\
\text { devem ser tratados } \\
\text { antes da disposição final } \\
\text { ambientalmente adequada. }\end{array}$ \\
\hline & $\begin{array}{c}\text { Medicamentos da classe } \\
\text { hormonais; antimicrobianos; } \\
\text { citostáticos; antineoplásicos; } \\
\text { imunossupressores; } \\
\text { digitálicos; imunomoduladores } \\
\text { e antirretrovirais, quando } \\
\text { descartados por serviços de } \\
\text { saúde, são enquadrados no } \\
\text { Grupo B mais os já descritos } \\
\text { pela Portaria MS } 344 / 98 \text { e } \\
\text { suas atualizações sobre } \\
\text { os medicamentos } \\
\text { de uso controlado. }\end{array}$ & $\begin{array}{c}\text { Produtos hormonais; } \\
\text { antimicrobianos; } \\
\text { citostáticos; antineoplásicos; } \\
\text { imunossupressores; } \\
\text { digitálicos; imunomoduladores; } \\
\text { antirretrovirais e produtos } \\
\text { farmacêuticos devem ser } \\
\text { tratados ou levados em } \\
\text { aterros de RSS perigosos, } \\
\text { classe 1. }\end{array}$ \\
\hline Material Radioativo & $\begin{array}{c}\text { Após o decaimento do } \\
\text { elemento radioativo a níveis } \\
\text { do limite de eliminação } \\
\text { estabelecidos pela norma } \\
\text { da Comissão Nacional de } \\
\text { Energia Nuclear (CNEN), } \\
\text { NE 6.05, o rótulo de REJEITO } \\
\text { RADIOATIVO deve ser retirado } \\
\text { e substituído por outro rótulo, } \\
\text { de acordo com o grupo do } \\
\text { resíduo em que se enquadrar. }\end{array}$ & $\begin{array}{c}\text { Quando o processo de } \\
\text { decaimento do elemento } \\
\text { radioativo atingir o nível do } \\
\text { limite de dispensa estabelecido } \\
\text { pelas normas vigentes, o rótulo } \\
\text { de REJEITO RADIOATIVO } \\
\text { deve ser retirado, } \\
\text { permanecendo a identificação } \\
\text { dos demais riscos presentes. }\end{array}$ \\
\hline cortante & $\begin{array}{l}\text { Os recipientes devem ser } \\
\text { substituídos quando o nível } \\
\text { de preenchimento atingir } \\
\text { 2/3 da capacidade total. }\end{array}$ & $\begin{array}{c}\text { Os recipientes de } \\
\text { acondicionamento dos RSS, } \\
\text { devem ser substituídos quando } \\
\text { o nível de preenchimento } \\
\text { atingir } 3 / 4 \text { da capacidade ou } \\
\text { de acordo com as instruções } \\
\text { do fabricante, sendo proibidos } \\
\text { seu esvaziamento manual } \\
\text { e seu reaproveitamento. }\end{array}$ \\
\hline
\end{tabular}

Fonte: os autores. 
Na sequência, conforme pode se observar na

Figura 2, estão apresentados os itens incluídos na legislação, com mudanças em todos os grupos da nova legislação sobre RSS.

Figura 2 - Itens incluídos na legislação sobre RSS - RDC 222/18.

\begin{tabular}{|c|c|}
\hline Grupos de resíduos & RDC 222/18 \\
\hline \multirow{4}{*}{$\begin{array}{l}\text { Grupo A } \\
\text { Resíduo infectante }\end{array}$} & $\begin{array}{l}\text { As seringas e agulhas podem ser desconectadas quando tiverem o dispositivo } \\
\text { de segurança. }\end{array}$ \\
\hline & $\begin{array}{l}\text { As bolsas de sangue e de hemocomponentes rejeitadas devem ser } \\
\text { acondicionadas em saco vermelho (A1) e transportadas em recipiente } \\
\text { adequado quando o tratamento for em local diferente da unidade geradora. }\end{array}$ \\
\hline & $\begin{array}{l}\text { Os cadáveres e carcaças de animais podem ter transporte diferenciado } \\
\text { de acordo com o órgão regulamentador. }\end{array}$ \\
\hline & $\begin{array}{l}\text { Os RSS referidos no caput (órgãos, tecidos e fluidos orgânicos de alta } \\
\text { infectividade para príons, de casos suspeitos ou confirmados) devem ser } \\
\text { segregados e acondicionados em saco vermelho duplo, como barreira de } \\
\text { proteção, e contidos em recipiente exclusivo devidamente identificado. }\end{array}$ \\
\hline \multirow[t]{3}{*}{$\begin{array}{l}\text { Grupo B } \\
\text { Resíduo químico }\end{array}$} & $\begin{array}{l}\text { As embalagens primárias de produtos de limpeza vazias podem ser } \\
\text { utilizadas para acondicionamento dos RSS do Grupo E, conforme } \\
\text { compatibilidade. }\end{array}$ \\
\hline & $\begin{array}{l}\text { Embalagens primárias vazias de produtos químicos com algum tipo de } \\
\text { periculosidade, depois de limpas com técnica correta, são consideradas } \\
\text { rejeitos e devem ser encaminhadas para descarte correto. }\end{array}$ \\
\hline & Somente embalagens vazias podem ser encaminhadas para reciclagem. \\
\hline \multirow{3}{*}{$\begin{array}{l}\text { Grupo C } \\
\text { Resíduo radioativo }\end{array}$} & $\begin{array}{l}\text { As sobras de alimentos provenientes de pacientes submetidos à terapia com } \\
\text { iodo 131, após acondicionadas, devem ter seu nível de radiação medido. }\end{array}$ \\
\hline & $\begin{array}{l}\text { Quando os valores de atividade ou de concentração de atividade forem } \\
\text { superiores aos níveis de dispensa, o resíduo de serviços de saúde deve } \\
\text { ser considerado como rejeito radioativo e deve observar as condições de } \\
\text { conservação de RSS de fácil putrefação. }\end{array}$ \\
\hline & $\begin{array}{l}\text { Quando os valores de atividade ou de concentração de atividade forem } \\
\text { inferiores ou iguais aos níveis de dispensa, os resíduos sólidos podem } \\
\text { ser descartados como resíduos do Grupo D e os resíduos líquidos na } \\
\text { rede coletora de esgotos com tratamento. }\end{array}$ \\
\hline \multirow[t]{2}{*}{$\begin{array}{l}\text { Grupo D } \\
\text { Resíduo comum }\end{array}$} & $\begin{array}{l}\text { Equipamentos de proteção individual (EPIs), desde que não apresentem } \\
\text { sinais ou suspeita de contaminação química, biológica ou radiológica, } \\
\text { podem ser descartados como RSS do Grupo D. }\end{array}$ \\
\hline & $\begin{array}{l}\text { Papel de uso sanitário e fralda, absorventes higiênicos, peças descartáveis } \\
\text { de vestuário, gorros e máscaras descartáveis, resto alimentar de paciente, } \\
\text { material utilizado em antissepsia e hemostasia de venóclises, luvas de } \\
\text { procedimentos que não entraram em contato com sangue ou líquidos } \\
\text { corpóreos, equipo de soro, abaixadores de língua e outros similares não } \\
\text { classificados como A1. }\end{array}$ \\
\hline \multirow[t]{3}{*}{$\begin{array}{l}\text { Grupo E } \\
\text { Resíduo perfurocortante }\end{array}$} & $\begin{array}{l}\text { Admite-se o emprego de tecnologia que promova o esvaziamento } \\
\text { automatizado de recipientes plásticos específicos com posterior } \\
\text { descontaminação, possibilitando sua reutilização. }\end{array}$ \\
\hline & $\begin{array}{l}\text { Os RSS do Grupo E, quando contaminados por agentes biológicos, químicos } \\
\text { e substâncias radioativas, devem ter seu manejo de acordo com cada classe } \\
\text { de risco associada. }\end{array}$ \\
\hline & $\begin{array}{l}\text { É permitida a separação do conjunto seringa agulha com auxílio de } \\
\text { dispositivos de segurança, sendo vedada a desconexão e o reencape } \\
\text { manual de agulhas. }\end{array}$ \\
\hline
\end{tabular}

Fonte: os autores. 


\section{Discussão}

Os resultados deste estudo evidenciam as exigências da atual legislação, e podem direcionar, informar e atualizar os profissionais que atuam no gerenciamento de resíduos. A comparação das duas legislações foi com foco nas mudanças práticas para os serviços de saúde evidenciando os itens que foram excluídos, mantidos e acrescentados nas novas determinações da atual legislação e poderá embasar os planos de adequações e melhorias na área de gerenciamento de RSS.

De modo geral, no Grupo A pode-se observar que a mudança se trata da forma de descarte de resíduos de vacinas; estes atualmente devem ser tratados antes de sua disposição final. No Grupo B quatro itens sofreram alterações. No Grupo C e no Grupo E apenas um item sofreu alteração.

O Grupo A abrange os RSS que obtiveram contato com algum tipo de material biológico; assim, o mesmo é considerado como resíduo infectante. ${ }^{(6)}$ Reitera-se que a mudança se trata da forma de descarte de resíduos de vacinas, que atualmente devem ser tratados antes da disposição final.

A primeira alteração refere-se ao tratamento dos produtos derivados de vacinação, sendo que não há mais a necessidade de serem devolvidos para as secretarias de saúde após o uso, caso o local de geração tenha tratamento correto de descarte. A RDC 222/18 define apenas que o tratamento adequado deve ocorrer antes do descarte dos resíduos. Isto traz impacto para as salas de vacinas de unidades básicas de saúde (UBSs) e clínicas de imunização.

Na RDC 222/18 seringas e agulhas podem ser desconectadas quando possuírem o dispositivo de segurança. Esta prática pode ser incorporada em decisão conjunta com o serviço de segurança do trabalho, para evitar acidentes de trabalho com perfurocortantes e, ainda, para análise de custos da compra deste dispositivo.

Segundo pesquisa que buscou identificar os motivos de acidentes de trabalho notificados em um hospital universitário do interior do estado de São Paulo, Brasil, foi evidenciado que, de 398 acidentes ocupacionais, 125 foram de perfurocortantes e 89 ocorreram em trabalhadores da enfermagem. As situações que mais foram relatadas são na administração de medicações $(23,62 \%)$ e soroterapia $(23,62 \%)$. Um total de $21,27 \%$ ocorreu durante o descarte em local incorreto, reencape de agulhas e descarte desses materiais. ${ }^{(11)}$

As bolsas de sangue e de hemocomponentes rejeitadas por qualquer tipo de evento de não uso devem ter tratamento antes do descarte final desses resíduos e devem ser transportadas em sacos na cor vermelha até destinação final, caso o serviço não conte com autoclave específica. ${ }^{(8)}$

Os hemocomponentes, quando receberam tratamento fora da unidade geradora, devem ser acondicionados em sacos na cor vermelha; órgãos, tecidos e fluídos com alta infectividade para príons devem ser acondicionados em saco vermelho duplo, como barreira de proteção, e contidos em recipiente exclusivo e devidamente identificado. ${ }^{(8)}$

No Grupo B quatro itens sofreram alterações. Os resíduos deste grupo são definidos como rejeitos químicos; são os que podem causar danos à saúde dos indivíduos, e foram melhor detalhados e descritos de forma mais objetiva, não permanecendo o sentido ambíguo da antiga legislação. ${ }^{(8)}$

Conforme a nova RDC 222/18, os resíduos em estado sólido devem ser dispostos de acordo com o risco que o mesmo apresente, ao contrário do que a antiga RDC 306/04 trazia (esses materiais deveriam ser descartados em aterros de resíduos perigosos, ou seja, classe 1). Caso o material não ofereça risco, pode ser encaminhado para outro tipo de destinação final; isso pode fazer com que os hospitais economizem para descarte de seus RSS, por facilitar a organização de licitações e contratos com as empresas que já operaram os outros tipos de resíduos. ${ }^{(8)}$

As embalagens primárias e até de produtos de limpeza, denominados como saneantes, podem ser utilizadas para acondicionamento dos RSS do Grupo E; por meio da RDC 222/18 é possível a utilização de garrafas $P E T$ para armazenar seringas, hábito anteriormente relatado em outro estudo 
por pacientes que fazem uso de insulina em suas residências. ${ }^{(12)}$ Para utilização das embalagens é necessário fazer uma tríplice lavagem. Já as embalagens primárias de produtos químicos com algum tipo de periculosidade são consideradas rejeitos e devem ser encaminhadas para descarte correto de resíduos químicos, e embalagens vazias podem ser encaminhadas para reciclagem. São dois pontos positivos da mudança, pois contribuem para a redução de custo hospitalar ao poder reutilizar essas embalagens e economizar com a compra de caixas coletoras. Ressalta-se que a RDC 222/18 determina que o rótulo deve ser autocolante e no padrão da Associação Brasileira de Normas Técnicas (ABNT), Norma ABNT NBR 7500. ${ }^{(8)} \mathrm{O}$ descarte de pilhas, baterias, acumuladores de carga e lâmpadas fluorescentes deve ser feito de acordo com as normas ambientais vigentes, sendo esta a norma regulamentadora. ${ }^{(8)}$ Pela RDC 306/04 esses produtos deveriam ser descartados de acordo com o CONAMA - Resolução no 257/1999. ${ }^{(6)}$

Outro ponto de mudança foi com relação às novas características de resíduos químicos, quando foram acrescentadas cardiogenicidade, teratogenicidade, mutagenicidade e quantidade. Essas novas características adicionadas auxiliam na compreensão dos produtos, o que possibilita diminuição das más interpretações dos mesmos. ${ }^{(8)}$

A última alteração deste grupo é a respeito do descarte de produtos farmacêuticos, sendo que os mesmos devem atender à regulamentação vigente, acrescidas as determinações da Portaria MS

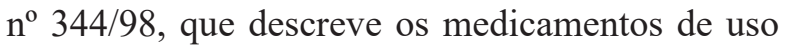
controlado e também os medicamentos da classe hormonais; antimicrobianos; imunossupressores; citostáticos; antineoplásicos; imunomoduladores; digitálicos; e antirretrovirais, quando descartados por serviços de saúde, farmácias, drogarias e distribuidores de medicamentos, ou apreendidos, e os resíduos e insumos farmacêuticos dos medicamentos, como dispunha a RDC 306/04. ${ }^{\left({ }^{(8)}\right.}$

As alterações que constam na RDC 222/18 referentes ao Grupo C estão registradas na Figura 1 e na Figura 2, caracterizadas por produtos com contaminação radiológica.
Os pontos acrescentados são a respeito das sobras de alimentos de pacientes que fazem terapia com iodo. Segundo a normativa, os rejeitos devem ser analisados quanto à medida de iodo presente nesses materiais, e acondicionados até que o nível de contaminação desse produto diminua, podendo, após esse processo, ser dispensado como resíduo do Grupo C. ${ }^{(8)}$

Quando o nível de decaimento for maior que o padronizado, o mesmo deve ser considerado como rejeito radioativo e será necessária uma avaliação do processo de acondicionamento dos resíduos de fácil putrefação; porém, caso o nível de decaimento seja menor que o padronizado, o rejeito pode ser dispensado como produto do Grupo $\mathrm{D}$ e resíduos líquidos podem ser liberados em rede de esgoto com tratamento. ${ }^{(8)}$

O local de acondicionamento deve conter os símbolos dos produtos presentes; todavia, quando a taxa de iodo estiver menor que o padronizado o rótulo/símbolo deve ser retirado, permanecendo os demais símbolos de identificação. ${ }^{(8)}$

Na prática, essa mudança é complexa e inviável, demanda muitas etapas e se aplica aos serviços de oncologia. Entretanto, não diminui a importância da verificação do decaimento referente às sobras de alimentos contaminados com iodo no processo de descarte dos resíduos e minimiza o impacto do descarte desse produto no meio ambiente quando descartado de forma irregular.

Alterações do Grupo D podem ser visualizadas na Figura 2. Na prática, esses resíduos são conhecidos como resíduos comuns recicláveis e não recicláveis; este grupo possui mudanças significativas para a gestão do ambiente hospitalar, sendo assim, a RDC 222/18 dispõe que materiais médicohospitalares e equipamentos de proteção individual (EPIs) que não entraram em contato com fluidos e secreções suspeitas de contaminação química, biológica ou radiológica, podem ser descartados como resíduos do Grupo D. Será necessário um trabalho de educação e parceria com as cooperativas ou parceiros de reciclagem, por esses produtos ou materiais possuírem uma identidade visual forte com o ambiente hospitalar. ${ }^{(8)}$ 
A normativa também traz alguns exemplos de materiais que comumente são descartados como resíduos do Grupo A, e que a partir da nova lei devem ser descartados como resíduos comuns, sendo eles: papel de uso sanitário e fralda, absorventes higiênicos, peças descartáveis de vestuário, gorros e máscaras descartáveis, resto alimentar de paciente, material utilizado em antissepsia e hemostasia de venóclises, luvas de procedimentos que não entraram em contato com sangue ou líquidos corpóreos, equipo de soro e abaixadores de língua. ${ }^{(8)}$

Anteriormente os profissionais eram orientados a descartar esses resíduos em coletores infectantes, com saco branco infectante, o que gerava uma visão de periculosidade. Pela nova legislação alguns desses insumos podem ser descartados como Grupo D, o que suscita um grande debate e ainda não existe consenso científico sobre o tema.

Essas mudanças trazem grandes alterações, principalmente dentro do ambiente hospitalar, visto que para o resíduo do Grupo A o transporte e a destinação final são pagos por quilograma para o descarte. Nesse sentido, a nova lei traz uma relevante redução de custo para o hospital.

Nesse ponto podemos começar um intenso debate sobre responsabilidade social e segurança social a respeito do assunto acima discutido, contudo faz-se necessário uma educação em serviços para os trabalhadores que recebem esse resíduo, para que os mesmos conheçam a procedência desses "resíduos hospitalares", fazendo com que, por conseguinte, gere menos resistência por parte dos trabalhadores das cooperativas, desde que sejam assegurados critérios de separação rigorosos desses resíduos nas unidades geradoras. Alterações do Grupo E estão descritas na Figura 1 e na Figura 2 , identificadas como resíduos perfurocortantes. É permitida também a separação do conjunto seringa e agulha, no entanto deve ser realizada com dispositivo de segurança; esse novo adendo permite que o local de descarte possa ser melhor utilizado, consequentemente diminuindo o número de acidentes de trabalho com perfurocortantes.
Os locais destinados ao alocamento dos RSS do Grupo E devem ser substituídos conforme a demanda do serviço e/ou quando o nível de preenchimento atingir $3 / 4$ da capacidade, sendo proibidos o esvaziamento manual e seu reaproveitamento. ${ }^{(8)}$ Essa nova mudança se contrapõe à anterior, a qual dizia que deveria ser trocado o local de descarte quando atingisse $2 / 3$ da capacidade. ${ }^{(6)}$ Com base nesse dado podemos entender que teremos menos desperdício de espaço da caixa de descarte; porém, em contraposição aumenta o risco de acidentes, já que a caixa destinada ao descarte estará mais cheia que o habitual.

A nova RDC traz mudanças impactantes para grande parte dos serviços de saúde, principalmente os hospitais, os quais agora podem descartar materiais não contaminados no lixo reciclável, o que diminui os gastos financeiros, uma vez que o resíduo infectante é pago para ser descartado.

De forma geral, podemos compreender que as principais mudanças são as embalagens primárias do Grupo B, que a partir da nova RDC podem ser usadas para acondicionamento de RSS, conforme a compatibilidade. A legislação nos trouxe que no Grupo D, os EPIs, desde que não apresentem nenhum sinal de contaminação, podem ser descartados como RSS do Grupo D. As novidades no Grupo E são que: seringas e agulhas podem ser desconectadas quando tiverem dispositivos de segurança; a partir da nova legislação é permitido o uso de tecnologia para esvaziamento automatizado de recipientes plásticos específicos com posterior descontaminação, possibilitando sua reutilização; se os resíduos foram contaminados por agentes biológicos, químicos ou radioativos, estes devem ter seu manejo de acordo com a classe de risco associada; e está proibido o reencape manual de agulhas.

No escopo da RDC 222/18, com a relevância da educação permanente em saúde, promovendo conhecimento e aprendizado para os profissionais, discutindo os acidentes de trabalho e também o uso consciente de materiais médico-hospitalares que darão origem aos RSS, visto que o gerenciamento adequado não é só o acondicionamento e a 
destinação adequados, espera-se uma diminuição da quantidade de resíduos gerados, uma vez que as taxas de geração permanecem com tendência de crescimento, sendo necessário gerenciamento de RSS mais seguro alinhado com as práticas globais de sustentabilidade em saúde.

\section{Conclusão}

Ao comparar as duas legislações, o presente estudo contribuiu para direcionar as adequações necessárias para atender a nova legislação com informações diretas para orientar novos critérios de classificação, acondicionamento, tratamento e destinação final para o gerenciamento seguro dos RSS em serviços de saúde.

Para atender às novas exigências da legislação os serviços de saúde devem minimamente cumprir os requisitos exigidos no Grupo A, Grupo B, Grupo C, Grupo D e Grupo E em todas as etapas de gerenciamento dos RSS.

O profissional enfermeiro precisa conhecer e se capacitar às novas legislações e, além disso, embasar-se com conhecimento científico para tornar seu trabalho mais assertivo e consistente, e, com isso, qualificar a tomada de decisão gerencial e poder promover mudanças dentro do seu ambiente de trabalho, contribuindo assim para o melhor planejamento do gerenciamento dos Resíduos de Serviços de Saúde dentro da sua instituição e impulsionar práticas gerenciais com foco na sustentabilidade em saúde.

Portanto, conclui-se que a RDC no 222/18 trouxe novas definições de critérios de classificação e responsabilidades legais, bem como avanços no gerenciamento de resíduos perigosos do Grupo A, e criou possibilidades de reaproveitamento, reuso e reciclagem de diversos itens. Com isso, torna-se necessário ser incorporada nas revisões dos planos de melhorias e planejamento estratégico para serem implementadas dentro dos PGRSS dos hospitais, favorecendo alinhamento com as práticas globais de segurança no trabalho, políticas ambientais voltadas ao meio ambiente e a sustentabilidade nos serviços de saúde.

\section{Referências}

1 Associação Brasileira de Empresas de Limpeza Pública e Resíduos Especiais (ABRELPE). Panorama de Resíduos Sólidos no Brasil: edição especial de 10 anos. [Internet]. São Paulo; 2016 [citado 2016 mar 22]. Disponível em: http:// www.abrelpe.org.br

2 Agapito N. Gerenciamento de resíduos de Serviço de Saúde. Grupo de Estudos Logísticos. [Internet]. 2007 [citado 2019 nov 17]. Disponível em: https://docplayer.com.br/859933Gerenciamento-de-residuos-de-servicos-desaude.html

3 Chaerul M, Tanaka M, Shekdar AV. A system dynamics approach for hospital waste management. Waste Management. [Internet]. 2008 [cited 2019 nov 17]; 28(2):442-49. Disponível em: https://doi.org/10.1016/j.wasman.2007.01.007

4 Hassan MM, Ahmed AS, Rahman KA, Biswas TK. Pattern of medical waste management: existing scenario in Dhaka City, Bangladesh. BMC Public Health. [Internet]. 2008 [cited 2019 nov 17]. Available from: https://www.ncbi.nlm. nih.gov/pmc/articles/PMC2254398/

5 Crema D, Carmo DRB, Turrin I, Silveira IR, Zotelli MFM, Paschoal MLH, et al. Gerenciamento de resíduos: a experiência de um hospital universitário. In: PROENF: Programas de Atualização em Enfermagem: Saúde do Adulto: Ciclo 2, Módulo 3. [Internet]. Porto Alegre: Artmed: Panamericana; 2007 [citado 2019 nov 17]. Disponível em: https://repositorio.usp.br/ item/002183981

6 Agência Nacional de Vigilância Sanitária (BR). Resolução RDC n ${ }^{\circ}$ 306, de 07 de dezembro de 2004. Dispõe sobre o Regulamento Técnico para o Gerenciamento de Resíduos de Serviços de Saúde. [Internet]. 2004 Dez 7 [citado 2021 out 12]. Disponível em: https://www.saude.mg.gov. br/images/documentos/res_306.pdf

7 Conselho Nacional do Meio Ambiente (BR). Resolução CONAMA n ${ }^{\circ} 358$, de 29 de abril de 2005. Dispõe sobre o tratamento e a disposição final dos resíduos dos serviços de saúde e dá outras providências. [Internet]. 2005 Abr 29 
[citado 2021 out 12]. Disponível em: https:// www.saude.mg.gov.br/images/documentos/ res_358.pdf

8 Ministério da Saúde - MS (BR). Resolução da Diretoria Colegiada - RDC n 222 , de 28 de março de 2018. Regulamenta as Boas Práticas de Gerenciamento dos Resíduos de Serviços de Saúde e dá outras providências. [Internet]. 2018 Mar 28 [citado 2021 out 12]. Disponível em: https://bvsms.saude.gov.br/bvs/saudelegis/ anvisa/2018/rdc0222_28_03_2018.pdf

9 Gil AC. Como elaborar projetos de pesquisa. 4a ed. São Paulo: Atlas; 2002.

10 Kripka RML, Scheller M, Bonotto DL. Documentary Research: consideration of concepts and features on Qualitative Research. Investigação Qualitativa em Educação. [Internet]. 2015 [cited 2019 nov 17]; (2):243-47. Available from: https://proceedings.ciaiq.org/index. php/ciaiq2015/article/view/252/248

11 Canini SRMS, Gir E, Hayashida M, Machado A. Needlestick injuries among nursing staff members at a university hospital in the interior of São Paulo State. Rev Latino-Am Enfermagem. [Internet]. 2002 [cited 2019 nov 17]; 10(2):172-78. Available from:http:// www.scielo.br/scielo.php? script $=$ sci arttext\&pid=S0104-11692002000200008\&lng $=$ en\&nrm $=$ iso

12 Alves SB, Souza ACS, Tipple AFV, Rezende $\mathrm{KCD}$, Rezende FR, Rodrigues ÉG. Management of waste generated in home care by the Family Health Strategy. Rev Bras Enferm. [Internet]. 2012 [cited 2019 nov 30]; 65(1): 128-34. Available from: http://www.scielo. br/scielo.php?script=sci_arttext\&pid=S0034$71672012000100019 \& \operatorname{lng}=$ en\&nrm=isso 
Carneiro, L. E.; Santos, G. A.; Nogueira, D. N. G. 